\title{
Testicular Torsion-Detorsion- Histological and Biochemical Changes in Rat Testis
}

\author{
Elshaari FA ${ }^{1}$, RI Elfagih ${ }^{1}$, Sheriff DS ${ }^{1 *}$ and Barassi IF $^{2}$ \\ ${ }^{1}$ Department of Biochemistry, Faculty of Medicine, Benghazi University, Benghazi, Libya \\ ${ }^{2}$ Department of Histology, Faculty of Medicine, Benghazi University, Benghazi, Libya
}

\section{Introduction}

Testicular torsion and detorsion are important clinical problems for infertile man. In fact, torsion of the spermatic cord is an emergency that results from rotation of the testis and epididymis around the axis of the spermatic cord. Male factor infertility accounts for up to half of all cases of infertility and affects one man in 20 in the general population [1]. While the annual incidence of testicular torsion is between one in 4,000 males and one in 158 males younger than 25 years, with peaks of incidence occurring in neonates and adolescents entering puberty $[2,3]$. Urgent operative interventions are required to re-establish the blood flow and circumvent the perpetual damaging effects on the testis which may turn out to be decreased spermatogenesis in majority of cases thus permanently lowering fertility chances [4].

Clinical and experimental data have shown that testicular torsion results in a spectrum of injuries dependent upon both the duration and degree of torsion [5]. Attempts at grading the severity of testicular injury after torsion have used such general parameters as fertility rates [6], testicular size, testicular weight, testicular histology [7], and semen analyses [8]. The results, however, have been conflicting. With 720-degree of torsion, several studies have reported reduction in testicular blood flow varying from $61.7 \%$ to $100 \%$ [5,9-11], with ischemic injury after periods of time as diverse as 1 hour and 8 hours of torsion [10-14]. In a rat model of testicular torsion, permanent loss of spermatogenesis is observed after torsion repair despite the return of blood flow [11].

As is evident from the literature reports, not much attempts have been made to investigate the effects of the torsion for the duration as early as $30 \mathrm{~min}$. followed by detorsion for the varying duration ranging from 1 hour to 1 week. Experimental models of testicular torsion are valuable tools to evaluate the relationship between the degree and duration of torsion with the blood flow and resultant damage to the torsed testes.

The present study was carried out with the purpose of determining the ill effects of early phase of ischemia and early to extended phase of reperfusion induced by testicular torsion / detorsion experimental animal model.

\section{Materials and Methods}

Seventy two male Sprague -Dawley rats were obtained from the Central Animal House of AL-Arab Medical University, Benghazi, Libya. All animals weighed between 250-270 g. The animals were housed in cages in groups of three in each colony. The colonies were maintained at room temperature and on a 12-hour light/dark cycle. All the animals had a free access to food and water. Animals were divided randomly into six groups (12 animals per group) in the following order:

Group 1: Sham operated control group (Cso) without the application of the torsion
Group 2: Torsion induced ischemia group (T30m): Ischemia was induced through torsion of spermatic cord for a period of $30 \mathrm{mins}$

Group 3: One hour reperfusion group after detorsion (T30mR1h)

Group 4: Twenty four hour reperfusion group after detorsion (T30mR24h)

Group 5: Forty eight hours reperfusion group after detorsion (T30mR48h)

Group 6: One week reperfusion group after detorsion (T30mR1wk)

\section{Experimental testicular torsion}

Adult male rats were anaesthetized using $20 \mathrm{mg} / \mathrm{ml}$ of xylazine and $10 \mathrm{mg} / \mathrm{ml}$ of ketamine and the testis was rotated as described [6]. Briefly, the testis was exteriorized through a low midline laparotomy, the gubernaculums was divided and the testis was freed from the epididymo-testicular membrane. The testis was torsioned $\left(720^{\circ}\right)$ and repositioned in the scrotum. The testis was kept wet using sterile normal saline soaked gauze. At the appropriate time the incision was reopened, the testis was counter-rotated to the natural position, the gubernaculum was rejoined, and the testis was reinserted into the scrotum via the inguinal canal. At the time of repair testes were examined and scored for apparent degree of ischemia and of reperfusion, respectively. Testes were collected at appropriate specified time intervals under the experimental conditions as above after the repair of torsion on a glass plate resting over crushed ice. The testes were homogenised by taking $1 \mathrm{~g}$ of tissue in a volume made to $10 \mathrm{ml}$ of ice cold $0.15 \mathrm{M} \mathrm{KCl}(10 \%$ w/v; $\mathrm{pH}$ adjusted to 7.4) using a Teflon Potter Elvenhjem homogenizer.

The homogenate was employed for the estimation of total protein [15]. The testicular lipids were extracted and purified [16] for the determination of phospholipids and cholesterol. The phosphorus was estimated [17] for calculating the content of phospholipids. The cholesterol was assayed by following the well established method [18]. Representative pieces of testis tissue were fixed in Bouin solution, embedded in paraffin, sectioned, and stained with hematoxylin and eosin (H\&E) for histolopathological examination.

Testicular biopsy scoring: To evaluate histopathological changes of the somniferous tubules for both experimental and control testis,

*Corresponding author: Dhastagir S Sheriff, Department of Biochemistry, Faculty of Medicine, Benghazi University, Benghazi, Libya, E-mail: dhastagir@yahoo.ca

Received January 23, 2012; Accepted March 08, 2012; Published March 12 , 2012

Citation: Elshaari FA, Elfagih RI, Sheriff DS, Barassi IF (2012) Testicular TorsionDetorsion- Histological and Biochemical Changes in Rat Testis. J Cytol Histol 3:136. doi:10.4172/2157-7099.1000136

Copyright: (C) 2012 Elshaari FA, et al. This is an open-access article distributed under the terms of the Creative Commons Attribution License, which permits unrestricted use, distribution, and reproduction in any medium, provided the original author and source are credited. 
Citation: Elshaari FA, Elfagih RI, Sheriff DS, Barassi IF (2012) Testicular Torsion-Detorsion- Histological and Biochemical Changes in Rat Testis. J Cytol Histol 3:136. doi:10.4172/2157-7099.1000136

the degree of damage for each section was evaluated [19]. Using 10X objective lens, ten tubules were scored for each sample. Seminiferous tubule profiles were evaluated and each was given a score from 1 to 10 on the basis of the criterion according to table 1. Scoring was based on 10 tubule profiles for each testis and the average for each score was recorded. Scores below 10 were considered evidence of impaired spermatogenesis.

Statistical analysis: Data were analyzed by a commercially available Statistical Package for Social Sciences (SPSS) program for Windows software. P-values $<0.05$ were regarded as statistically significant. Oneway Analysis of Variance (ANOVA) test was performed and post hoc multiple comparisons were done with least-squares differences (LSD).

\section{Results}

A) The effects of ischemia/reperfusion on spermatogenesis, in testicular tissue are presented in as micrographs showing the level of damage caused by testicular torsion/ detorsion compared to the control (Cso) and testicular biopsy scores for the testicular sections from the different groups Figure 1A-1F and Table 1.

Primary testicular disease is the most common cause of male infertility in which patients present with late spermatogenic arrest or tubular atrophy [20]. Cross sections of testes from, controls sham operated, Csp; Torsion, T30 mins and reperfused, T30mins.R1h; T30 mins.R24h; T30mins R48h; T30 mins.R1wk groups of experimental animals were examined for disruption of spermatogenesis and changes were illustrated (Figure 1).

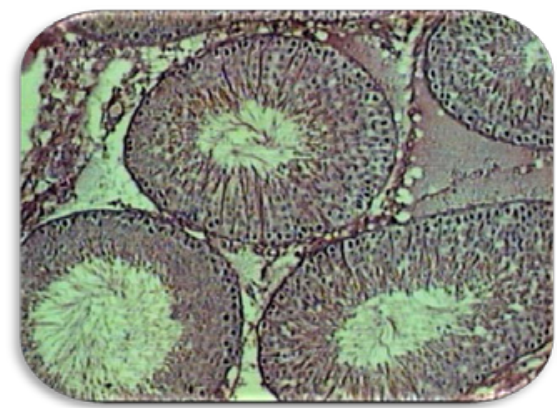

Figure 1a: Photomicrograph of a cross section of testis from sham operated animal (hematoxylin and eosin staining). Seminiferous tubules showing normal spermatogenesis, exhibiting all stages of spermatogenic cells including abundant spermatozoa. Magnification- $10 \mathrm{X}$.

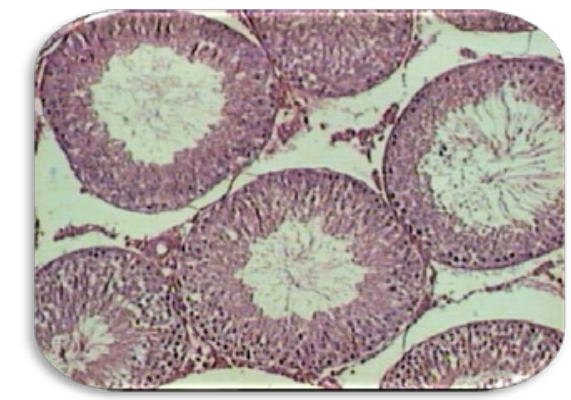

Figure 1b: Non-recovery ischemic testis (hematoxylin and eosin staining). Seminiferous tubules showing normal spermatogenesis, exhibiting all stages of spermatogenic cells including abundant spermatozoa. Some sloughing and tissue disorganization are noted. Magnification $10 \mathrm{X}$.

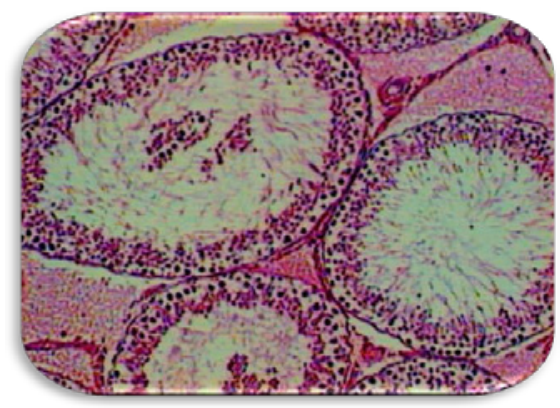

Figure 1c: Photomicrograph of a cross section from 1 hour recovery (hematoxylin and eosin staining). Seminiferous tubules showing mildly affected spermatogenesis, exhibiting all stages of spermatogenic cells including abundant spermatozoa. Severe sloughing and disorganization are noted Magnification $10 \mathrm{X}$.

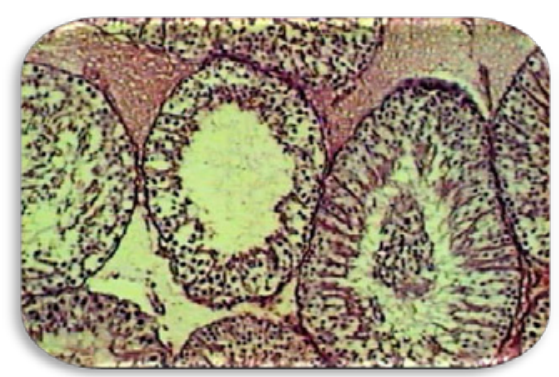

Figure 1d: Photomicrograph of a cross section from 24 hour recovery (hematoxylin and eosin staining). Seminiferous tubules showing sever sloughing and disorganization. Damage is at the level spermatozoa, spermatids and some spermatocytes. The interstitial is disorganized and contains some blood. Magnification $10 \mathrm{X}$.

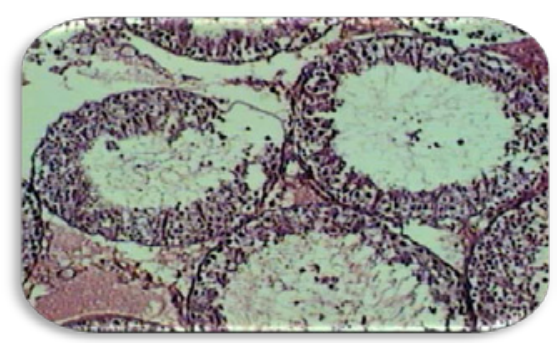

Figure 1e: Photomicrograph of a cross section from 48 hour recovery (hematoxylin and eosin staining). Seminiferous tubules showing sloughing and disorganization. Damage is at the level spermatozoa, spermatids and some spermatocytes. The interstitial is disorganized and contains some blood. Magnification $10 \mathrm{X}$.

Sham operated rats demonstrated normal seminiferous tubule morphology and no obvious damage was inflicted on the testis of the control sham operated group of experimental animals (Figure 1). This was demonstrated by the high testicular biopsy score of $9.3 \pm 0.7(\mathrm{M} \pm$ $\mathrm{SD}$ ) recorded for this group (Table 1).

Cross sections from testes having received a 30 mins, $720^{\circ}$ testicular torsion. T30 mins group of animals had seminiferous tubules showing normal spermatogenesis with some sloughing and tissue disorganization (Figure 1B) and also demonstrated by the testicular biopsy score of $8.7 \pm 1.5(\mathrm{M} \pm \mathrm{SD})$ recorded for this group (Table 1).

Cross sections from testes of animal group, T30 mins. R1h, reperfused for $1 \mathrm{~h}$ by testicular detorsion employing anti clockwise 


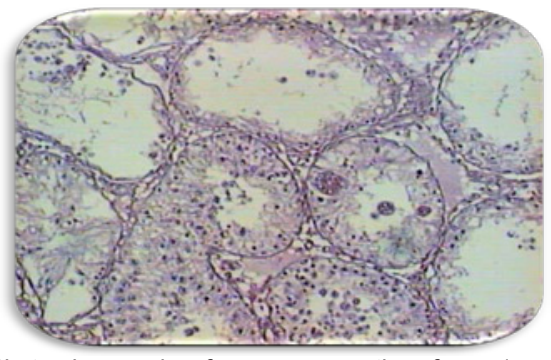

Figure 1f: Photomicrograph of a cross section from 1 week recovery (hematoxylin and eosin staining). Seminiferous tubules showing sloughing and disorganization. Damage is at the level of spermatozoa, spermatids, spermatocytes and spermatogonia. The interstitial is disorganized and contains some blood. Sertoli's cells formed multinuclear giant cells. Some tubules are affected at the level of Sertoli's cells. Magnification $10 \mathrm{X}$.

rotation of spermatid cord after the testicular torsion for $30 \mathrm{mins}$, showed seminiferous tubules with mildly affected spermatogenesis. Severe sloughing and tissue disorganization was noted (Figure 1C). The testicular biopsy score of $9.1 \pm 0.7(\mathrm{M} \pm \mathrm{SD})$ was obtained (Table1).

Cross sections from testes of animal group, T30 mins R24h reperfused for 24 hours detorsion after testicular torsion of $30 \mathrm{mins}$, duration exhibited seminiferous tubules with severe sloughing and disorganization. Damage was at the spermatozoa, spermatids and some spermatocytes level. The interstitial was disorganized and contained some blood (Figure 1D.). The testicular biopsy score of $8.3 \pm 1.7(\mathrm{M} \pm \mathrm{SD})$ was observed (Table 1).

Cross sections from testes of animal group, T30mins R48h, reperfused for 48 hours after testicular torsion of 30 mins, duration depicted sloughing and disorganization of seminiferous tubules.
Damage was at the level of spermatozoa, spermatids and some spermatocytes. The interstitial was disorganized and contained some blood (Figure 1E). The observed testicular biopsy score of $6.7 \pm 1.3(\mathrm{M} \pm \mathrm{SD})$ indicated progressive severity in the impairment of spermatogenesis (Table1).

Cross sections from testes of animal group, T30mins R1 week, reperfused for 1 week after testicular torsion of 30 mins. Duration showed sloughing and disorganization of seminiferous tubules. Damage was at the level of spermatozoa, spermatids, spermatocytes and spermatogonia. The interstitial was disorganized and contained some blood. Sertoli's cells formed multinuclear giant cells. Some tubules were affected at the level of Sertoli's cells (Figure 1F). The observed testicular biopsy score of $2.8 \pm 2.5(\mathrm{M} \pm \mathrm{SD})$ indicated progressive severity in the spermatogenesis (Table1).

The effects of ischemia / reperfusion injury on the levels of total protein in rat testicular tissue are denoted in Table 2.

It became evident from the data that the protein level was significantly lower in torsioned testis group compared to the sham operated control group. After 1 hour reperfusion the levels rose significantly compared with torsed testis and control groups. The protein content started declining with the increase in the duration of reperfusion and by 1 week the protein content reached almost the control group level.

Table 3 represents the alterations observed in phospholipids as a result of ischemia/reperfusion over different periods of reperfusion after torsion for 30 minutes.

When observations were expressed as per milligram of protein, phospholipid levels did not alter significantly in torsed testis and

\begin{tabular}{|c|c|c|c|c|c|c|c|}
\hline \multirow{2}{*}{ Score } & \multirow{2}{*}{ Description } & \multicolumn{6}{|c|}{ Groups } \\
\hline & & $\mathrm{C}_{\mathrm{so}}$ & $T_{30 \min }$ & $T_{30 m} R_{1 h}$ & $T_{30 m} R_{24 h}$ & $T_{30 m} R_{48 h}$ & $T_{30 m} R_{1 w k}$ \\
\hline 10 & $\begin{array}{l}\text { Complete spermatogenesis with many mature } \\
\text { and shed spermatozoa present. The germinal } \\
\text { epithelium originated normally and an open } \\
\text { lumen is evident. }\end{array}$ & $4^{*}$ & $4^{*}$ & $3^{*}$ & $1^{*}$ & & \\
\hline 9 & $\begin{array}{l}\text { Many shed spermatozoa but the germinal } \\
\text { epithelium disorganized with marked sloughing. }\end{array}$ & $5^{*}$ & $3^{*}$ & $5^{*}$ & $6^{*}$ & $1^{*}$ & \\
\hline 8 & $\begin{array}{l}\text { Few spermatozoa (<5-10 per tubular cross- } \\
\text { section) are present but many round and } \\
\text { elongated spermatids are evident. }\end{array}$ & $1^{*}$ & & $2^{*}$ & $1^{*}$ & $2^{*}$ & \\
\hline 7 & $\begin{array}{l}\text { No spermatozoa are present but many round and } \\
\text { elongated spermatids are evident. }\end{array}$ & & $2^{*}$ & & $1^{*}$ & $1^{*}$ & \\
\hline 6 & $\begin{array}{l}\text { Few spermatids ( }<5-10 \text { per tubular cross-section) } \\
\text { are present but many spermatocytes are evident. }\end{array}$ & & $1^{*}$ & & & $5^{*}$ & \\
\hline 5 & $\begin{array}{l}\text { Many spermatocytes are present, but there are } \\
\text { no spermatids or spermatozoa. }\end{array}$ & & & & & $1^{*}$ & $1^{*}$ \\
\hline 4 & $\begin{array}{l}\text { Few spermatocytes }(<5-10 \text { per tubular cross- } \\
\text { section) are present but there are no spermatids } \\
\text { or spermatozoa. }\end{array}$ & & & & $1^{*}$ & & $1^{*}$ \\
\hline 3 & Spermatogonia are the only germ cells present. & & & & & & $3^{*}$ \\
\hline 2 & Only sertoli cells are present. & & & & & & $5^{*}$ \\
\hline 1 & No cells are evident in the tubule. & & & & & & \\
\hline \multicolumn{2}{|c|}{ Mean \pm SD } & $9.3 \pm 0.7$ & $8.7 \pm 1.5$ & $9.1 \pm 0.7$ & $8.3 \pm 1.7$ & $6.7 \pm 1.3$ & $2.8 \pm 2.5$ \\
\hline
\end{tabular}

*= Average of scores in cross sections of each group of testes based on number of tubule/ section.

$\mathbf{C}_{\mathrm{so}}=$ Control, sham operated; $\mathbf{T}_{30 \mathrm{~min}}=$ torsion for 30 minutes; $\mathbf{R}=$ reperfusion for 1 hour $\left(\mathbf{R}_{1 \mathrm{~h}}\right)$, 24 hours $\left(\mathbf{R}_{24 \mathrm{~h}}\right)$, 48 hours $\left(\mathbf{R}_{48 \mathrm{~h}}\right)$, and 1 week $\left(\mathbf{R}_{1 \mathrm{wk}}\right)$

Scoring was based on 10 tubule profiles for each testis and the average for each score was recorded. Scores below 10 were considered evidence of impaired spermatogenesis.

Table 1: Testicular biopsy scores for the testicular sections from the different groups. 
Citation: Elshaari FA, Elfagih RI, Sheriff DS, Barassi IF (2012) Testicular Torsion-Detorsion- Histological and Biochemical Changes in Rat Testis. J Cytol Histol 3:136. doi:10.4172/2157-7099.1000136

\begin{tabular}{|c|c|c|c|c|c|c|}
\hline Parameter & $\mathrm{C}_{\mathrm{so}}$ & $\mathbf{T}_{30 \min }$ & $\mathbf{T}_{30 \mathrm{~m}} \mathbf{R}_{1 \mathrm{~h}}$ & $\mathbf{T}_{30 \mathrm{~m}} \mathbf{R}_{24 \mathrm{~h}}$ & $T_{30 m} R_{48 h}$ & $\mathbf{T}_{30 \mathrm{~m}} \mathbf{R}_{1 \mathrm{wk}}$ \\
\hline $\begin{array}{l}\text { Total protein } \\
\mathrm{mg} / \mathrm{mg} \text { protein }\end{array}$ & $29.7 \pm 4.1$ & $24.3 \pm 2.8^{a}$ & $35.8 \pm 3.4^{\mathrm{a}, \mathrm{b}}$ & $31 \pm 1.8^{b}$ & $28.2 \pm 7.08^{c}$ & $28.3 \pm 4.4^{c}$ \\
\hline
\end{tabular}

*Number of animals in each group $=12 ; a, b, c, d$, e: Significant at $P<0.05$.

$a=$ when compared to Cos; $b=$ when compared to $T_{30 m} ; c=$ when compared to $T_{30 \mathrm{~m}} R_{1 \mathrm{~h}}$;

$\mathrm{C}_{\mathrm{so}}=$ Sham operated control; $\mathrm{T}=$ torsion; $\mathrm{R}=$ reperfusion (time duration shown as subscript).

Table 2: The effect of testicular torsion and detorsion on total protein concentration expressed as microgram per gram of fresh tissue; values are represented as mean \pm standard deviation (SD).

\begin{tabular}{|c|c|c|c|c|c|c|}
\hline Groups* & $C_{\text {so }}$ & $\mathbf{T}_{30 \min }$ & $\mathbf{T}_{30 \mathrm{~m}} \mathbf{R}_{1 \mathrm{~h}}$ & $\mathbf{T}_{30 \mathrm{~m}} \mathbf{R}_{24 \mathrm{~h}}$ & $\mathbf{T}_{30 \mathrm{~m}} \mathbf{R}_{48 \mathrm{~h}}$ & $\mathbf{T}_{30 \mathrm{~m}} \mathbf{R}_{1 \mathrm{wk}}$ \\
\hline $\begin{array}{l}\text { phospholipid } \\
\text { (a) } \mathrm{mg} / \mathrm{millig} \text { ram protein }\end{array}$ & $0.175 \pm 0.01$ & $0.156 \pm 0.01$ & $0.188 \pm 0.04$ & $0.230 \pm 0.1$ & $0.157 \pm 0.02$ & $0.146 \pm 0.02^{d}$ \\
\hline
\end{tabular}

*Number of animals in each group $=12$; a, b. c, d, e: Significant at $\mathrm{P}<0.05$.

$a=$ when compared to Con; $b=$ when compared to $T_{30 \mathrm{~min}} ; c=$ when compared to $T_{30 \mathrm{~m}} R_{1 \mathrm{~h}}$; $d=$ when compared to $T_{30 \mathrm{~m}} R_{24 \mathrm{~h}}$;

$\mathrm{C}_{\mathrm{so}}=$ Control, sham operated; $\mathrm{T}=$ Torsion; $\mathrm{R}=$ Reperfusion (time duration shown as subscript).

Table 3: The effect of testicular torsion and detorsion on phospholipid concentration expressed as: ( a) milligram per milligram protein. (b) Milligram per gram of fresh tissue; values are represented as mean \pm standard deviation (SD).

\begin{tabular}{|c|c|c|c|c|c|c|}
\hline Groups & $\mathrm{C}_{\mathrm{so}}$ & $\mathbf{T}_{30 \min }$ & $\mathbf{T}_{30 \mathrm{~m}} \mathbf{R}_{\mathbf{1 h}}$ & $\mathbf{T}_{30 \mathrm{~m}} \mathbf{R}_{24 \mathrm{~h}}$ & $\mathbf{T}_{30 \mathrm{~m}} \mathbf{R}_{48 \mathrm{~h}}$ & $\mathbf{T}_{30 \mathrm{~m}} \mathbf{R}_{1 \mathrm{wk}}$ \\
\hline $\begin{array}{l}\text { Cholesterol } \\
\text { (a) } \mathrm{mg} / \mathrm{millig} \text { ram } \\
\text { protein }\end{array}$ & $0.0102 \pm 0.003$ & $0.0143 \pm 0.0034^{a}$ & $0.008 \pm 0.001^{b}$ & $0.008 \pm 0.002^{b}$ & $0.01 \pm 0.003$ & $0.006 \pm 0.0008^{\mathrm{a}, \mathrm{b}, \mathrm{e}}$ \\
\hline
\end{tabular}

*Number of animals in each group=12; a, b. c, d, e: Significant at $P<0.05$.

$a=$ when compared to $C_{s 0} ; b=$ when compared to $T_{30 \min } ; c=$ when compared to $T_{30 m} R_{1 h}$;

$d=$ when compared to $T_{30 m} R_{24} ; e=$ when compared to $T_{30 m} R_{48 h}$;

$\mathrm{C}_{\mathrm{so}}=$ Control, sham operated; $\mathrm{T}=$ Torsion; $\mathrm{R}=$ Reperfusion (time duration shown as subscript).

Table 4: The effect of testicular torsion and detorsion on cholesterol concentration expressed as: (a) milligram per milligram protein. (b) Milligram per gram of fresh tissue; values are represented as mean \pm standard deviation (SD).

reperfusion groups except in 1week reperfusion group a significant decline was observed compared to 24hours reperfusion group. After 1 hour reperfusion, the phospholipid levels significantly increased compared with torsed testis and control groups. Thereafter, the levels declined with the increase in reperfusion duration in which 24 and 48hours reperfusion groups showed a significant decrease compared to 1 hour reperfusion group, and the phospholipid levels were lowered compared with 1 hour and 24 hours reperfusion groups in 1 week of the reperfusion. The data on the effects of varying durations of reperfusion following testicular torsion on the cholesterol level are exhibited in Table 4.

The cholesterol levels when expressed on the basis of per milligram protein were significantly increased in torsed testis group compared with the control group. Following reperfusion for a period of 1 hour to 1 week, there was a significant decrease in cholesterol level compared to control and torsed testis groups except for 48 hours reperfusion group which did not show any significant alteration.

\section{Discussion}

Previous studies in a rat model of testicular torsion found that a $720^{\circ}$ rotation is virtually sufficient to eliminate testicular blood flow
$[9,11]$ and that reperfusion begins immediately after the repair of torsion and the blood flow returns to control value [9].

Spermatogenesis is an extremely active replicative process. The high rates of cell division inherent in this process imply correspondingly

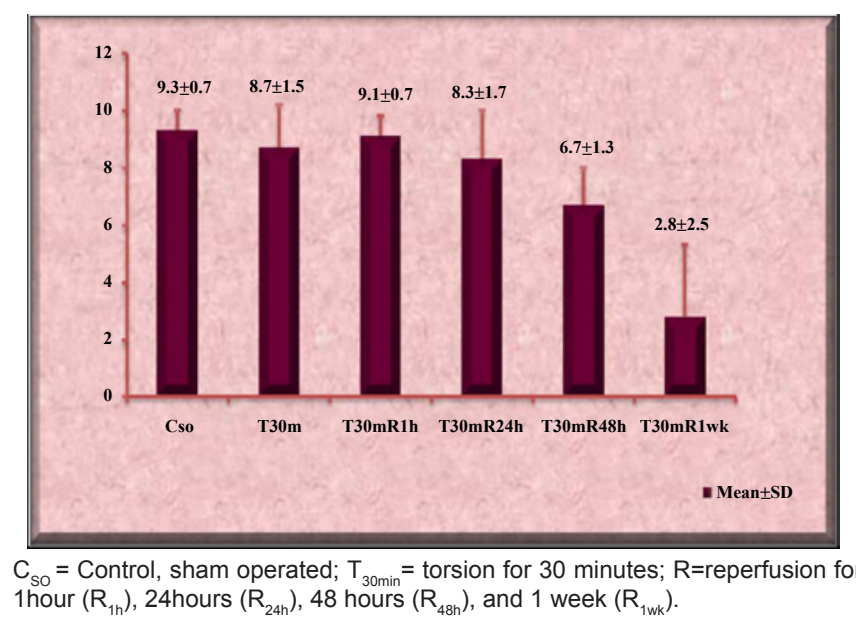

Figure 2: Tesitular Biopsy Score from Different Groups. 
high rates of mitochondrial oxygen consumption by the germinal epithelium. However, Oxygen tensions in this tissue are low because of the poor vascularization of the testes. The low oxygen tension that characterizes this tissue may be an important component of the mechanisms by which the testes protects itself from free radicalmediated damage.

But with the torsion, both spermatogenesis and Leydig cell steroidogenesis are vulnerable to oxidative stress. In general, free radical generation that exceeds the capacity of antioxidant defenses results in oxidative stress which possibly elicits irreversible degenerative responses or necrosis in living cells [21].

In the present study, the histopathological changes observed in the testicular tissue on torsion and detorsion indicate the effect of ischemia in a designated period of 30 minutes and is evident from the score (table 1) and the cross sectional view of Photomicrograph (Figure 1B). While Seminiferous tubules show normal spermatogenesis, and exhibit all stages of spermatogenic cells including abundant spermatozoa, however, some sloughing and tissue disorganization has set in. This could possibly be due to the initiation of degenerative process as a result of increased lipid peroxidation and the cellular ATP depletion. In one of the previous study, extensive apoptosis is a phenomenon that occurs regularly in the germinal epithelium of the contralateral testis in testicular torsion. Specifically primary and secondary spermatocytes are predominantly affected. Notably spermatogonia, capillary endothelium, connective tissue and peritubular fibroblasts are rarely involved. The trauma to the blood-testis barrier initiated by testicular torsion induces the release of apoptotic activating factors (cytokines), which subsequently cause extensive apoptosis in the germinal epithelium of the contralateral testis. Therefore, it is probable that repeat apoptotic episodes may explain the high incidence of infertility in these patients [22]. the decline in the testicular membrane constituents, protein and phospholipid, content in the present study lend support to this contention. The cholesterol content, however, was raised, perhaps due to the accumulation in the face of reported decline in testicular androgen production suggesting $\mathrm{I} / \mathrm{R}$ stress might play a role in Leydig cell dysfunction, as well as by acting directly in germ cell apoptosis [23]. Similar observations have been reported in the literature in higher period of torsion earlier.

The photomicrograph of the cross section of the testes after 1 hour of reperfusion shows mildly affected spermatogenesis with severe sloughing and tissue disorganization (Figure 1C). Slight improvement in the scoring (Table 1) might be due to the regaining of blood supply and with this the supply of nutrients and oxygen. The significantly elevated protein contents and cholesterol showing reverse trend also support our observation of the improvement in the tissue histology in this group of animals.

Further reperfusion over a period of 24 hours, 48 hours and 1 week indicate progressive deterioration in testicular histology at the level of spermatozoa, spermatids and some spermatocytes with severe sloughing and disorganization. Additionally, a significant appearance of sertoli's cells becoming multinuclear giant cells with some tubules getting affected at the level of Sertoli's cells in 1 week reperfusion (Figure 1F).

The formation of multinucleated cells, constituted by young spermatids have been shown in another study [22], similar observations in rats using D-thio-glucose were reported earlier [23]. This is a compound that interferes with glucose metabolism [24]. It may indicate some kind of change on the spermatogenic cycle.

The observed testicular biopsy score of $9.1 \pm 0.7$ in 1 hour reperfusion to $2.8 \pm 2.5(\mathrm{M} \pm \mathrm{SD})$ in 1 week reperfusion indicate progressive severity with time (Table 1). The progressive histopathological damage in the testicular tissue with the increase in the duration of reperfusion may be accounted with the progressive oxidative stress, encountered in oxygen supply, leading to lipid peroxidation of the tissue membranes and initiation of the apoptotic events. The progressive decline in the testicular protein, phospholipid and cholesterol with the increasing duration of the reperfusion in the present study further weigh the possibility of generation and accumulation of toxic reactive oxygen species that may damage several cellular components by lipid peroxidation of cell membrane lipids. Unilateral testicular torsion is a pathological process that affects stages VI-XI of cycle of the seminiferous epithelium (CSE) in the contralateral non-twisted testis in torsion/detorsion and torsion/ orchiectomy states. These, coincidentally, are the stages that express low SOD levels [22-25]. Moreover, post-ischemic reperfusion, conditions that lead to selective death of germ cells in vivo, caused the very long chain poly unsaturated fatty acids (VLCPUFA) to disappear from the testicular sphingomyelin and cerebrosides of adult fertile rats, showing that these lipids are specific traits of spermatogenic cells [26,27].

Torsion/detorsion develops a precipitating state of oxidative stress in the testes and impairing the latter's ability to produce viable spermatozoa capable of initiating and supporting embryonic development.

\section{Acknowledgement}

We would like to thank to $\mathrm{Dr}$. Ahmad Erhoma chairman of 23rd July polyclinic Dr. Ahmad Gerryo, and laboratory technical staff of polyclinic especially Mrs. Naja El-Titaly and Mr. Osama Al-Orfee for their sincere help. We would also like to thank Dr. Noor El-deen Dagmaan, Dr. Salah Al-Gmatty from Al Fatah Children's Hospital for their kind help.

\section{References}

1. McLachlan RI, de Krester DM (2001) Male infertility: the case for continued research. Med J Aust 174: 116-117.

2. Williamson RC (1976) Torsion of the testis and allied conditions. Br J Surg 63 465-476.

3. Anderson JB, Williamson RC (1986) The fate of the human testes following unilateral torsion of the spermatic cord. Br J Urol 58: 698-704.

4. Perotti M, Badger W, Prader S, Moran ME (2006) Medical malpractice in urology, 1985 to 2004: 469 consecutive cases closed with indemnity payment J Urol 176: 2154-2157.

5. Palmer JS, Plzak LF, Cromie WJ (1997) Comparison of blood flow and histological changes in rat models of testicular ischemia. J Urol 158: 11381140 .

6. Anderson JB, Williamson RC (1990) Fertility after torsion of the spermatic cord $\mathrm{Br} J$ Urol 65: 225-230.

7. Hadziselimovic F, Geneto R, Emmons LR (1998) Increased apoptosis in the contralateral testes of patients with testicular torsion as a factor for infertility. $J$ Urol 160: 1158-1160

8. Anderson MJ, Dunn JK, Lipschultz LI, Coburn M (1992) Semen quality and endocrine parameters after acute testicular torsion. J Urol 147: 1545-1550.

9. Becker EJ, Prillaman HM, Turner TT (1997) Microvascular blood flow is altered after repair of testicular torsion in the rat. J Urol 157: 1493-1498.

10. Turner TT (1985) Acute experimental testicular torsion. No effect on the contralateral testis. J Androl 6: 65-72. 
Citation: Elshaari FA, Elfagih RI, Sheriff DS, Barassi IF (2012) Testicular Torsion-Detorsion- Histological and Biochemical Changes in Rat Testis. J Cytol Histol 3:136. doi:10.4172/2157-7099.1000136

11. Turner TT, Brown KJ (1993) Spermatic cord torsion: loss of spermatogenesis despite return of blood flow. Biol Reprod 49: 401-407.

12. Nguyen L, Lievano G, Ghosh L, Radhakrishnan J, Fornell L, et al. (1999) Effect of unilateral testicular torsion on blood flow and histology of contralateral testes. J Pediatr Surg 34: 680-683.

13. Gezici A, Ozturk H, Buyukbayram H, Ozturk H, Okur H (2006) Effects of gabexate mesilate on ischemia-reperfusion-induced testicular injury in rats. Pediatr Surg Int 22: 435-441.

14. Beheshtian A, Salmasi AH, Payabvash S, Kiumehr S, Ghazinezami B, et al. (2008) Protective effects of sildenafil administration on testicular torsion/ detorsion damage in rats. World J Urol 26: 197-202.

15. Lowery OH, Rosebroug NV, Farr AL, Rendall RJ (1951) Protein measurement with the folin phenol reagent. J Biol Chem 193: 256-275.

16. Folch J, Ascoli I, Lees M, Meath JA, LeBaron N (1951) Preperation of Lipid extracts from brain tissues. J Biol Chem 91: 833-841.

17. Marinetti GV (1962) Chromatographic separation, identification and analysis of phosphatides. J Lipid Res 3: 111-120.

18. Bloor WR, Pelkan KF, Allen DM (1922) Determination of fatty acids and cholesterol in small amount of blood plasma. J Biol Chem 52: 191-205.

19. Johnsen SG (1970) Testicular biopsy score count - a method for registration of spermatogenesis in human testes: normal values and results in 335 hypogonadal males. Hormones 1: 2-25.
20. Jequier AM, Holmes SC (1993) Primary testicular disease presenting as azoospermia or oligozoospermia in an infertility clinic. Br J Uro 71: 731-735.

21. Buttke TM, Sandstrom PA (1994) Oxidative stress as mediator of apoptosis. Immunol Today15: 7-10.

22. Hadziselimovic F, Geneto R, Emmons LR (1998) Increased apoptosis in the contralateral testes of patients with testicular torsion as a factor for infertility. $J$ Urol 160: 1158-1160.

23. Turner TT, Lysiak JJ, Shannon JD, Nguyen QA, Bazemore-Walker CR (2006) Testicular torsion alters the presence of specific proteins in the mouse testis as well as the phosphorylation status of specific proteins. J Androl 27: 285-293.

24. Turner TT, Bang HJ, Lysiak JJ (2005) Experimental testicular torsion: reperfusion blood flow and subsequent testicular venous plasma testosterone concentrations. Urology 65: 390-394.

25. Vigueras RM, Reyes G, Rojas-Castañeda J, Rojas P, Hernández R (2004) Testicular torsion and its effects on the spermatogenic cycle in the contralatera testis of the rat. Lab Anim 38: 313-320.

26. Neumann $F$ (1984) Effects of drugs and chemicals on spermatogenesis. Arch Toxicol Suppl 7: 109-117.

27. Furland NE, Zanetti SR, Oresti GM, Maldonado EN, Aveldano MI (2007) Ceramides and sphingomyelins with high proportions of very long-chain polyunsaturated fatty acids in mammalian germ cells. J Biol Chem 282: 18141 18150. 